\title{
Artigos
}

\section{Discursos sobre o cuidado em saúde de Lésbicas, Gays, Bissexuais, Travestis, Transexuais (LGBT) entre médicas(os) da Estratégia Saúde da Família*}

\section{Discourses on the healthcare of lesbian, gay, bisexual, and transgender (LGBT) people adopted by doctors working in Brazil's Family Health Strategy} (abstract: p. 15)

\section{Discursos sobre el cuidado de la salud de Lesbianas, Gais, Bisexuales, Travestis, Transexuales (LGBT) entre médicas(os) de la Estrategia Salud de la} Familia (resumen: p. 15)

\section{Danilo Borges Paulino(a)}

<dbpaulino@ufu.br>

\section{Emerson Fernando Rasera ${ }^{(\mathrm{b})}$ <emersonrasera@ufu.br> (iD}

Flavia do Bonsucesso Teixeira ${ }^{(\mathrm{c})}$ <flavia.teixeira@ufu.br> iD

\author{
Este artigo é resultado da \\ Dissertação de Mestrado "Discursos \\ sobre o acesso e a qualidade \\ da atenção integral à saúde da \\ população LGBT entre médicos(as) \\ da Estratégia Saúde da Família", do \\ Programa de Pós-graduação em \\ Psicologia da Universidade Federal \\ de Uberlândia, de autoria de Danilo \\ Borges Paulino e orientação de \\ Emerson Fernando Rasera. \\ (a,c) Departamento de Saúde \\ Coletiva, Faculdade de Medicina, \\ Universidade Federal de Uberlândia \\ (UFU). Avenida Pará, 1720, bloco \\ $2 \mathrm{U}$, sala 8, bairro Umuarama. \\ Uberlândia, MG, Brasil, 38400-902. \\ (b) Instituto de Psicologia, UFU. \\ Uberlândia, MG, Brasil.
}

Objetiva-se identificar os discursos sobre o acesso e a qualidade da atenção integral à saúde da população de Lésbicas, Gays, Bissexuais, Travestis e Transexuais (LGBT) entre médicas(os) da Estratégia Saúde da Família, refletindo sobre como esses discursos podem impactar o cuidado em saúde da população LGBT. Participaram 15 médicas(os) em Uberlândia e Belo Horizonte, Minas Gerais, Brasil. A análise das entrevistas seguiu os pressupostos teóricos do Construcionismo Social. Foram construídas três categorias de análise: "Discurso da não diferença", "Discurso do não saber" e "Discurso do não querer". Foi possível compreender como esses discursos são potencializadores do silenciamento de questões envolvendo as condições de saúde da população LGBT, afastando-a do cuidado em saúde integral, equânime e universal. Concluímos que o melhor atendimento dessa população depende de mudanças na atuação dos profissionais de saúde, sendo urgente sua formação e qualificação para uma saúde LGBT integral.

Palavras-chave: Minorias sexuais e de gênero. Saúde pública. Acesso aos serviços de saúde. Assistência integral à saúde. 


\section{Introdução}

Ela resolvera procurar um ginecologista. [...] Durante a consulta, quando perguntada pelo histórico de suas parcerias sexuais anteriores, Inês informou que nunca teve relaçôes com homens. [...] Ela foi medicada e encaminhada para realizar exames complementares, entre eles uma ultrassonografia endovaginal. [...] A tentativa de introdução do equipamento no canal vaginal causou dor e esta sensação foi informada à profissional que realizava o procedimento. [...] Não suportando a situação, Inês disse que era "virgem” e expressóes faciais de susto e descrédito tentaram ser inibidas (ou reforçadas!) com perguntas do tipo: "como assim? Você nunca teve penetração? Qual a sua idade?" ao que seguiu uma resposta constrangida "nunca tive relaçốes com homens”. [...] Inês não retornou mais àquela profissional e quiçá tenha retornado a outro ginecologista ou profissional de saúde ${ }^{1}$. (p. 13-4)

As questóes apontadas pela médica que realizava o exame evidenciam aspectos importantes da relação estabelecida entre profissionais de saúde e pessoas que se identificam ou são identificadas como pertencentes ao segmento composto por Lésbicas, Gays, Bissexuais, Travestis e Transexuais (LGBT). Foram relatos assim que construíram a demanda por essa pesquisa. Produziram debates e inquietaçóes sobre o cuidado em saúde ofertado a essa população, particularmente em relação aos(às) médicos(as) de família e comunidade que trabalham na Estratégia Saúde da Família (ESF), permitindo formar a urdidura para tecer os fios narrativos acerca do acesso e da qualidade da atenção integral aos(às) usuários(as) LGBT no Sistema Único de Saúde (SUS).

Criada em março de 1994 como um Programa, a ESF configura as dimensóes das práticas de saúde no Brasil em aspectos territoriais, populacionais e das ações desenvolvidas nesses territórios ${ }^{2}$. Ela tem papel fundamental no primeiro contato, na longitudinalidade e na coordenação do cuidado; e, quando resolutiva, implica a ampliação do acesso às demandas dos usuários. Apesar da expansão da ESF em todo o território nacional nos últimos anos, existem importantes diferenças na cobertura e no acesso e na oferta de cuidados nos municípios, com impactos relevantes no acesso e uso dos serviços de saúde 3 .

De modo geral, a demanda dos movimentos organizados LGBT envolve reivindicações nas áreas dos direitos civis, políticos e sociais, o que exige atuação articulada e coordenada de todas as áreas do Poder Executivo ${ }^{4}$. No cenário internacional $^{(\mathrm{d})}$, aponta-se que a população LGBT experiencia múltiplas disparidades no cuidado em saúde e tem menos acesso aos serviços e cuidados em saúde. Usuários(as) LGBT citam a falta de educação do(a) trabalhador(a), a recusa de tratamento, cuidado precário e abuso verbal por parte dos(as) profissionais como barreiras ao cuidado; e, como resultado, muitos(as) evitam tratamento médico, mesmo nas situações de emergência 5 . No cenário nacional, aponta-se que a atuação médica em questóes de sexualidade se mostra limitada para o atendimento integral e humanizado em situaçóes de violência sexual e saúde geral para a população LGBT'6 . (d) As pesquisas internacionais aqui citadas foram traduzidas diretamente de um outro contexto internacional ao contexto brasileiro ou de Minas Gerais. Objetivamos, assim, potencializar o que é fornecido pelas pesquisas nacionais, apontando semelhanças que demonstram que esse trabalho também pode ter relevância em outros cenários. 
Nesse mesmo cenário, o discurso médico sustenta a patologização de identidades e práticas sexuais socialmente discordantes da norma, o que legitima e reproduz processos discriminatórios ${ }^{7}$. Também no Brasil, a assistência à população LGBT desafia os profissionais a desenvolverem açóes de cuidado que superem a histórica abordagem estigmatizante, associada à própria construção dessas categorias identitárias como pertencentes ao rol de patologias pelo discurso médico-científico ${ }^{8}$.

Com base nas ideias de Cecílio", essencialmente, é possível perceber que as necessidades em saúde, na verdade, são definidas pelas particularidades de cada sujeito, nos diversos encontros e relaçốes que estabelece e constrói com os sujeitos de uma equipe de saúde, como o(a) médico(a), por exemplo. Dessa forma, o que se espera não é negar as especificidades em saúde da população LGBT (re)afirmadas pelo discurso médico-científico, mas, sim, ampliar a discussão e o entendimento dessas necessidades para o contexto da determinação social do processo saúde-adoecimento-cuidado de cada sujeito, articulando as diferentes dimensóes da vida envolvidas, considerando os aspectos: históricos, econômicos, sociais, culturais, biológicos, ambientais e psicológicos que configuram uma determinada realidade sanitária ${ }^{10}$.

A qualificação consistente em atenção à saúde da população LGBT é rara, o que leva a crer que esforços futuros serão necessários para desenvolver, nos currículos médicos, esse tema, de modo a prover cuidado à população LGBT que tem suas necessidades únicas e demanda médicos(as) competentes e devidamente treinados(as) ${ }^{5}$.

É objetivo deste trabalho identificar os discursos sobre o acesso e a qualidade da atenção integral à saúde da população LGBT entre médicas(os) da Estratégia Saúde da Família, refletindo sobre como esses discursos podem reiterar o exposto anteriormente e, até mesmo, impactar o cuidado em saúde da população LGBT.

\section{Método}

Participaram desta pesquisa médicas(os) que atuam nas Unidades Básicas que operam na lógica organizativa da Estratégia Saúde da Família dos municípios de Uberlândia e Belo Horizonte, em Minas Gerais. Foram realizadas 5 (cinco) entrevistas em Uberlândia e 10 (dez) entrevistas em Belo Horizonte. A explicação para essa quantidade de entrevistadas(os) está na divisão de cada um desses municípios em distritos sanitários, sendo que a cidade de Uberlândia contava com 5 (cinco) e a cidade de Belo Horizonte com 9 (nove) distritos sanitários, no momento da realização das entrevistas. Em Belo Horizonte, para além dos 9 (nove) distritos sanitários, seria realizada uma entrevista em um dos aglomerados da cidade. Entretanto, pela dificuldade de acesso geográfico a essa Unidade, em especial pelo fato de os(as) pesquisadores(as) não contarem com uso de veículo próprio para condução na cidade, optou-se por substituí-la por outra Unidade de Saúde da Família (USF), localizada no território de maior vulnerabilidade da cidade, conforme orientaçóes repassadas pela Prefeitura Municipal. Todas(os) as(os) entrevistadas(os) foram selecionadas(os) aleatoriamente por meio de sorteio. Para cada distrito sanitário de cada cidade foi realizado um sorteio envolvendo todas as Unidades de Saúde da Família daquele distrito, de onde apenas uma foi sorteada (à exceção do distrito sanitário de Belo Horizonte que selecionou duas Unidades no mesmo sorteio). 
Todas(os) as(os) médicas(os) selecionadas(os) foram convidadas(os) a participar livremente da pesquisa e, após concordarem, assinaram termo de consentimento livre e esclarecido. As entrevistas foram realizadas pelo autor principal deste trabalho, seguiram roteiro semiestruturado, foram gravadas e, na sequência, transcritas em sua íntegra. Os temas abordados na entrevista foram: o papel da USF na Rede de Atenção à Saúde do município, a USF e o Atendimento à População LGBT, a organização e qualidade da atenção à saúde da população LGBT, e a Política Nacional de Saúde Integral LGBT. Para preservar a identidade das(os) médicas(os) entrevistadas(os), seus nomes reais foram substituídos por nomes fictícios. O quadro 1 sintetiza o perfil das(os) médicas(os) entrevistadas(os) nesta pesquisa.

Quadro 01. Participantes da pesquisa.

\begin{tabular}{|c|c|c|}
\hline $\begin{array}{c}\text { Nome } \\
\text { (fictício) }\end{array}$ & $\begin{array}{l}\text { Idade } \\
\text { (anos) }\end{array}$ & $\begin{array}{c}\text { Tempo de Atuação na } \\
\text { ESF (anos) }\end{array}$ \\
\hline Adolfo" & 43 & 12 \\
\hline Anastácia\# & 24 & 6 meses \\
\hline Cláudia"\# & 27 & 1,5 \\
\hline Diógenes"\# & 46 & 20 \\
\hline Fabíola\# & 28 & 4 meses \\
\hline Gael $^{\#}$ & 37 & 8 \\
\hline Hilda $^{\# \#}$ & 27 & 2 \\
\hline Isabela\# & 30 & 6 meses \\
\hline Joice\# & 35 & 5 \\
\hline Noêmia”\# & 34 & 8,5 \\
\hline Olga & 46 & 15 \\
\hline Pietro\# & 42 & 12 \\
\hline Rogério\# & 44 & 14 \\
\hline Sueli & 28 & 7 meses \\
\hline Zilda $^{\#}$ & 41 & 16 \\
\hline
\end{tabular}

\# Belo Horizonte. \#\# Uberlândia

Fonte: dos próprios autores.

A análise das entrevistas seguiu os pressupostos teóricos do Construcionismo Social. A esse respeito, segundo Burr ${ }^{11}$, nós não podemos investigar o mundo psicológico e social usando apenas nossas presunções e práticas. Ou seja, nossas práticas de pesquisa devem ter a linguagem como foco de interesse, uma vez que os usos e efeitos da linguagem são de central importância para os construcionistas sociais. Assim, se a explicação do fenômeno apresentada pelo(a) pesquisador(a) tem o caráter de conhecimento ou verdade como um resultado da "voz da ciência", as explicações trazidas pelas outras pessoas envolvidas nesse processo, como por exemplo as pessoas que responderam às entrevistas, deveriam ser igualmente consideradas no mesmo. Burr (1995) também afirma que muitos pesquisadores construcionistas sociais acreditam que os objetivos da pesquisa não deveriam ser a descoberta dos "fatos", mas sim a mobilização do processo de pesquisa para se alcançar um objetivo diferente. Ou seja, a pesquisa não deveria ser em busca de uma verdade, mas por qualquer utilidade que a leitura que o(a) pesquisador(a) faz de um fenômeno tenha em trazer mudanças para 
aqueles que precisam, o que transformaria a pesquisa em pesquisa-ação e em uma atividade política. Para ela ${ }^{11}$, os discursos são transindividuais por não estarem alocados em pessoas particulares, mas por existirem em uma comunidade linguística. O desafio é criar categorias que falem de processos sócio-linguísticos que atravessam as falas das pessoas, e não categorias que falem das pessoas em si. Assim sendo, não foram foco desta análise os aspectos relacionados à idade, renda, cor, religião, formação e tempo de atuação na Estratégia Saúde da Família das(os) entrevistadas(os). A autora apresenta a desconstrução como sendo uma estratégia viável para realizar essa análise ${ }^{11}$.

A primeira ação da desconstrução é a revelação de contradiçôes. Nesta pesquisa a revelação de contradiçóes deu aos pesquisadores a possibilidade da construção das categorias de análise, intituladas "Discursos do Não" e que serão apresentadas a seguir. Observou-se que, no início de cada entrevista, ao definir acesso e qualidade, as(os) entrevistadas(os) traziam o conceito de acesso como a capacidade de acolher e cuidar de todos(as) os(as) usuários(as) com integralidade. Entretanto, ao longo da entrevista, em especial quando elas(es) relatavam exemplos de atendimentos e situaçóes envolvendo a população LGBT, o "Não" era um termo constante, revelando as contradições entre o conceito de acesso dito no início da entrevista e aquele demonstrado na prática dos serviços de saúde no acolhimento e na qualidade do acesso e da atenção integral à saúde da população LGBT no SUS.

A etapa seguinte da desconstrução é o desenvolvimento de maneiras atuais de entender discursos e representaçóes sobre pessoas e sociedades e mostrar como "verdades" atuais foram constituídas, como elas são mantidas e quais relaçôes de poder elas carregam. Nesta pesquisa essa etapa da análise foi feita, quando os "nãos" presentes nas entrevistas foram compreendidos em três grandes categorias, a saber: "Não diferença”, "Não saber” e "Não querer”. Tão logo ocorreu essa compreensão, foi possível perceber como esses discursos transindividuais eram utilizados pelas(os) entrevistadas(os) para justificar a forma de atender e cuidar da população LGBT na Estratégia Saúde da Família no SUS, mostrando como essas "verdades" estão construídas e mantidas em nossa sociedade, explicitando as relaçóes de poder que atravessam a interface médico(a)-paciente da população LGBT.

Por fim, tem-se, na desconstrução, a análise de discurso, na qual os discursos são examinados e suas identidades e implicações de poder são trazidas à tona. Nesta pesquisa, essa etapa da análise foi feita após a construção de cada categoria, quando a leitura dos pesquisadores encontrou e debateu com a literatura que trata do assunto e que cabe nos limites impostos a este texto. Assim, foi possível compreender as características presentes em cada discurso, bem como os impactos dessas construçóes discursivas no acolhimento e na qualidade do acesso e da atenção integral à saúde da população LGBT no SUS.

Este estudo deriva da pesquisa "Análise do Acesso e da Qualidade da Atenção Integral à Saúde da População LGBT no Sistema Único de Saúde”, coordenada pelo Núcleo de Saúde Pública da Universidade de Brasília e financiada pelo Ministério da Saúde. O estudo é de abrangência nacional e contempla as cinco regiôes. Está de acordo com as normas da Resolução no 466/12 e da Resolução no 510/2016 do Conselho Nacional de Saúde (CNS), e foi apresentado e aprovado pelo Comitê de Ética em Pesquisa da UnB, número do parecer 652.643. 


\section{Análise e discussão}

Foram construídas três categorias de análise, que denominamos "Discursos do Não”, apresentadas a seguir. Esses discursos foram selecionados por sua recorrência na maior parte das entrevistas realizadas.

\section{O "Discurso da não diferença"}

O "Discurso da não diferença” é utilizado pelas(os) médicas(os) de família e comunidade ao afirmarem que não há diferenças entre a população LGBT e as demais populaçôes atendidas por elas(es). O "Discurso da não diferença" parece ser usado como uma estratégia para afastar a mensagem do preconceito que, na sua dobra, denuncia o aspecto moral presente nas construções discursivas. Assim, a tentativa é de minimizar a diferença, sob o argumento de uma suposta igualdade. Contudo, um dos efeitos dessa fala é a negação do outro. Trata-se da contradição não percebida. Aqui, a ideia é a de que igualdade faz desaparecer (ou mesmo impede que surja) o preconceito, em uma equação aparentemente simples, lógica e socialmente correta e aceitável, e que cumpre a função de apagar o próprio sujeito.

A entrevista de Fabíola é atravessada pelo "Discurso da não diferença”, quando ela reflete sobre qual deveria ser o local ideal para o cuidado em saúde da população LGBT no SUS bem como sobre quais agravos os(as) acometeriam.

"Por que ter um ambulatório diferente, né? Eles estão sujeitos às mesmas doenças. Se você fica falando que eles têm um direito a mais, você fica, já tá colocando eles, diferenciando eles como uma população maior de risco.” (Fabíola, 28 anos, Belo Horizonte)

Fabíola questiona a necessidade de um ambulatório específico para o cuidado LGBT. O preconizado seria que todos(as) tivessem acesso e atendimento garantido com qualidade na Estratégia Saúde da Família, porta de entrada do SUS ${ }^{12}$. Porém, a justificativa é de que as pessoas LGBT estão sujeitas às mesmas doenças da população em geral. Essa concepção difere da percepção de Daniel \& Butkus ${ }^{13}$, para os quais, embora os membros da comunidade LGBT enfrentem problemas de saúde semelhantes aos da população em geral, as pessoas LGBT são mais propensas a identificar-se como estando em más condições de saúde em relação aos indivíduos heterossexuais, e diferentes segmentos da população LGBT têm riscos e necessidades em saúde específicos. Ao considerar que o princípio da equidade se materializaria em um "direito a mais", oblitera-se uma outra possibilidade que seria a de discutir que a população LGBT historicamente tem sido posicionada em um lugar de restrição de direitos.

Estudos investigando a saúde física das pessoas LGBT e, comparando com os(as) heterossexuais, apontam que as populações LGB têm maiores taxas de incapacidade, limitaçôes físicas e pior saúde geral e, com poucas exceções, raras pesquisas tiveram como foco específico o estado de saúde de pessoas transexuais ${ }^{14}$. Aqui é possível perceber como essas publicaçôes (re)posicionam a população LGBT, reiteram o discurso médico-científico e, se por um lado demonstram as necessidades de saúde específicas, de outro parecem associar a sexualidade não heterossexual a uma doença 
ou mesmo naturalizar certas comorbidades a essas identidades (propensão a depressão, transtornos mentais, comportamentos aditivos, etc.). A histórica luta dos movimentos LGBT permanece atual e, na disputa por sentidos, a reivindicação seria pelo afastamento da ideia de anormal, do patológico, e por uma compreensão mais integral do sujeito na sua relação com os serviços e o Sistema de Saúde.

Para Gael, o "Discurso da não diferença” é acionado ao se falar sobre as doenças e/ou agravos que mais acometem a população LGBT atualmente. Aqui é possível perceber como as necessidades em saúde da população LGBT são silenciadas pelo "Discurso da não diferença".

Entrevistador: "E, na sua opinião, quais seriam as doenças e/ou agravos que mais acometem a população LGBT atualmente?”

Gael: "Eu acho que seria na mesma, pelo que tenho visto, minha opinião, seria na mesma sequência que a gente tem visto na outra. Infecçóes respiratórias, lombalgias, cefaleias, depressão... então acompanharia aproximadamente a mesma população, dos que me procuraram eu não vi essa diferenciação muito grande aí não.” (Gael, 37 anos, Belo Horizonte)

Gael reflete sobre a população LGBT que já atendeu na USF em que atua, dizendo não ter visto "essa diferenciação muito grande aí não". Importante observar que, em momento algum da entrevista, foi dito a Gael que existia alguma diferença em relação às doenças e/ou agravos que mais acometem a população LGBT. Talvez pela estruturação da pergunta ele supôs que provavelmente existiria diferença. Afinal, se não existisse, por que perguntar especificamente da população LGBT se poderíamos interrogar em relação à população em geral, já que, a princípio, seriam todos(as) iguais? Porém, mesmo que tenha reconhecido isso na estruturação da pergunta do entrevistador, Gael acionou o "Discurso da não diferença”, negando a suposta especificidade anunciada. A sua experiência, a partir do cotidiano de trabalho, parece ser o elemento autorizativo escolhido para sustentar uma suposta igualdade.

Adolfo refere dúvidas quanto às demandas da população LGBT. Para ele, também parece não haver diferenças entre as demandas:

Entrevistador: "E, na sua opinião, os demais membros da equipe estão preparados para atender às demandas da população LGBT?” Adolfo: "Pois é, eu precisava saber primeiro as demandas. "O que é a demanda LGBT, especificamente?”. Eu acho que isso seria o principal, pois eu acredito que a demanda em saúde, da comunidade LGBT, é a mesma demanda em saúde da população real. Não consigo perceber alguma coisa tão específica deles.” (Adolfo, 43 anos, Belo Horizonte)

Adolfo utiliza o termo "população real", como se a população LGBT não o fosse. A irrealidade da população LGBT estaria ancorada na negação da homossexualidade/ bissexualidade/transexualidade/travestilidade como expressóes válidas do humano. Esse discurso opera (re)produzindo uma população virtual, hipotética. Tornar-se real ainda é muito necessário para que a vida real das pessoas LGBT seja tão digna e plena em direitos e em obrigaçóes quanto às da maioria que vive - ou diz viver - nos 
parâmetros da norma heterossexual ${ }^{15}$. Nesse sentido, Daniel \& Butkus ${ }^{13}$ buscam demonstrar que a equidade no cuidado em saúde da população LGBT deve também ser atravessada pela interseccionalidade. Os autores afirmam que a população LGBT enfrenta uma série de desafios comuns dentro do Sistema de Saúde, que vão desde o acesso aos serviços de saúde até situações que reforçam estigmas sociais, marginalização e discriminação, e que, embora haja progressos na redução das disparidades de saúde na comunidade LGBT, muito mais precisa ser feito para alcançar a equidade para as pessoas LGBT no sistema de saúde.”13

\section{O "Discurso do não saber"}

O "Discurso do não saber" foi identificado quando as(os) entrevistadas(os) afirmavam não saber quais são as demandas da população LGBT. Esse discurso também compreende as falas dessas(es) médicas(os) que, quando interpeladas(os) por algum assunto relacionado às questôes de saúde da população LGBT, diziam não saber sobre ou, mesmo, não ter conhecimento desse tema.

Vale ressaltar que a questão primordial aqui é o uso do discurso. Alguém pode usar esse discurso mesmo tendo tido qualificação. Não se trata de ele ser falso ou verdadeiro. As pessoas usam discursos para construir fatos, e esse entendimento é fundamental para essa análise. Iniciamos a análise do "Discurso do não saber" pela resposta de Anastácia quando interpelada sobre quais doenças e/ou agravos ela consideraria que mais acometem essa população atualmente.

"Sinceramente, eu não tenho muito, muito embasamento pra te falar isso não. Então, acho melhor não dar minha opinião, porque eu não tenho muito embasamento pra te responder, não.” (Anastácia, 24 anos, Belo Horizonte)

Para Anastácia, não há embasamento para falar sobre o assunto e, consequentemente, responder a algumas perguntas. Ela não sabe e, consequentemente, não pode falar. Portanto, não se trata de não querer falar, mas de não ter condiçôes de falar.

Essa fala de Anastácia produz uma inquietação a partir da aparente tranquilidade com que assegura o "não saber". Essa posição, ao mesmo tempo que parece anunciar que “isso não é problema meu”, está em dissonância com o lugar de suposto saber historicamente ocupado pela medicina. Pode um(a) médico(a) não saber? Afinal, que tipo de embasamento é necessário para se falar sobre as condiçóes de saúde da população LGBT? A "Association of American Medical Colleges" (AAMC) ${ }^{13}$ recomendou que os currículos das escolas médicas devem garantir que os(as) estudantes dominem habilidades, atitudes e conhecimentos necessários para promover um excelente e amplo cuidado para pacientes LGBT, ao incluir conteúdo abrangente e que aborde as necessidades específicas do cuidado em saúde dos(as) pacientes LGBT, além de permitir o treino em habilidades de comunicação com pacientes e colegas sobre as questóes de orientação sexual e identidade de gênero.

As Diretrizes Curriculares Nacionais (DCN) dos cursos de graduação em Medicina ${ }^{16}$ abordam de forma ampla a questão de gênero e sexualidade. A sigla LGBT não aparece nesse documento, nem mesmo a palavra sexualidade. Em seu artigo 5o, as DCN afirmam que: 
$\mathrm{Na}$ Atenção à Saúde, o graduando será formado para considerar sempre as dimensões da diversidade biológica, subjetiva, étnico-racial, de gênero, orientação sexual, socioeconômica, política, ambiental, cultural, ética e demais aspectos que compóem o espectro da diversidade humana que singularizam cada pessoa ou cada grupo social $[\ldots]^{16}$. (p. 1-2)

As palavras gênero e orientação sexual são citadas apenas mais uma vez nesse documento, em seu artigo 12, item II, subitem c):

[...] postura ética, respeitosa e destreza técnica na inspeção, apalpação, ausculta e percussão, com precisão na aplicação das manobras e procedimentos do exame físico geral e específico, considerando a história clínica, a diversidade étnicoracial, de gênero, de orientação sexual, linguístico-cultural e de pessoas com deficiência ${ }^{16}$. (p. 5)

Ainda que as demandas e o conhecimento sobre a população LGBT sejam pouco discutidos nos documentos que orientam os cursos de graduação em Medicina no Brasil, e que estejam incluídos em um bojo de outras tantas singularidades dos sujeitos e coletividades, orientação sexual e gênero, apresentados como mais um assunto a se considerar na formação ética, de forma ampla e genérica, eles estão presentes. Essa abordagem pode ser insuficiente, porém é indicativa de que o aparente conforto do "não saber" pode ser questionado a partir das mesmas normas que o regulam.

O relato de Fabíola constitui mais um exemplo do uso desse discurso:

"Como eu não sei, eu tenho que ter alguém me falando "olha isso aqui é importante olhar”. Eu não sei, então assim, chegasse alguém com mais conhecimento do que eu a respeito disso e falasse "olha gente...” igual eu só tô olhando o lado psicológico, mas alguém chegasse e falar "olha não é só o lado psicológico, tem essas outras questóes pra olhar”, porque eu não sei. Pra mim é geralmente só o lado psicológico mesmo, mas é a minha... ignorância a respeito do tema, eu não sei outras questôes. Por isso que eu preciso de alguém pra me instruir.” (Fabíola, 28 anos, Belo Horizonte)

Fabíola, ao recorrer ao "Discurso do não saber", diz de um certo alguém, que cumpriria o papel de instruí-la. Essa afirmação da médica pode remeter ao modelo bancário de educação analisado por Paulo Freire, no qual os professores são reduzidos a sistemas robotizados de fornecimento de currículo, lendo instruçóes de um roteiro para estudantes que são, eles mesmos, reduzidos a máquinas que repetem a orientação recebida ${ }^{17}$, modelo ainda hegemônico na formação médica brasileira.

No entanto, ao nomear alguém que poderia "instruí-la", uma área do conhecimento é acionada como autorizada a falar: a ciência psi. $\mathrm{O}$ acionamento do componente psi reatualiza o discurso médico-científico acerca da homossexualidade e da transexualidade, identificadas como transtornos ou como causadoras de transtornos.

O uso do "Discurso do não saber" parece justificar o fato de as(os) médicas(os) não acolherem adequadamente a população LGBT. Sabe-se dos desafios cotidianos dos(as) médicos(as) frente a outras situaçốes de adoecimentos ou agravos, que não envolvem 
especificamente a população LGBT, com as quais eles(as) eventualmente não tiveram qualificação para lidar, e o enfrentamento muitas vezes é feito sem que se acione o "discurso do não saber" para justificar a ausência de cuidado. O fato de supostamente não terem treinamento não é justificativa em si para negligenciarem o atendimento. Ou seja, essa parece ser uma das poucas situações em que o "não saber" protege o profissional.

Noêmia reitera a falta de formação para cuidar da população LGBT:

"Não sei te falar, talvez a gente poderia ter capacitação para isso, para melhorar o nosso atendimento a essa população, eu me vejo um pouco despreparada nesse sentido, igual você me pergunta "Quais são as dificuldades e tudo", eu não sei mesmo. Então talvez falte capacitação né, para nós nesse sentido.” (Noêmia, 34 anos, Uberlândia)

Noêmia conclui que falta formação e capacitação para cuidar das pessoas LGBT. Entretanto, não foi preocupação desse estudo identificar o processo de formação das pessoas entrevistadas. A recorrência de suas falas não poderia passar despercebida e, no cenário de disputas, revelam que não se trata apenas de denunciar a ausência de formação para cuidar da população LGBT, mas, sim, de se ter uma justificativa para o não atendimento ou o atendimento não adequado às pessoas LGBT.

Além disso, muitas vezes, o "Discurso do não saber" estrutura-se por meio de uma culpabilização do sistema pelo não saber. Ou seja, não se sabe por que não houve ensino da temática durante a graduação ou por que a gestão municipal não ofereceu ação de educação permanente com esse tema. Uma estratégia que também esconde a desresponsabilização, ou seja, "eu não sei e posso continuar não sabendo".

O cuidado primário em saúde à população LGBT é comprometido por deficiências em conhecimentos e habilidades específicas em relação à população LGBT entre profissionais de saúde ${ }^{18}$. Entretanto, a desresponsabilização é uma estratégia que atua amplamente, e outras questóes também afastam a população LGBT do cuidado em saúde, como: ambientes inóspitos nos serviços de saúde que estigmatizam os(as) pacientes LGBT e a falta de políticas e parâmetros para uma melhor prática ${ }^{19}$.

Ao longo de todas as entrevistas realizadas foi possível perceber também que o "Discurso do não saber" é reiterado por todas(os) as(os) médicas(os) entrevistadas(os) nesta pesquisa, quando dizem do seu não conhecimento acerca da Política Nacional de Saúde Integral da População LGBT ${ }^{4}$.

\section{O "Discurso do Não Querer"}

O “Discurso do Não Querer” busca justificar a ausência da população LGBT nos serviços de saúde em razão de uma associação de negativas que se articulam a partir de decisóes individuais. Ou seja, por que os(as) usuários(as) LGBT não querem, por que não têm demandas ou necessidades em saúde, e, finalmente, por que não têm necessidades específicas de saúde.

O impacto desse discurso produz um apagamento das demandas em saúde da população LGBT, bem como tende a desqualificar a necessidade de açóes específicas para as pessoas LGBT. Uma vez que as necessidades não são explicitadas/reconhecidas, 
a equipe e o Sistema de Saúde se eximem de qualquer responsabilidade ou ação em prol do cuidado em saúde dessas pessoas.

Começamos a análise do funcionamento desse discurso com a fala de Rogério: "Porque esse negócio é o seguinte, às vezes a própria pessoa mesmo desiste, talvez o paciente não quer mais falar sobre isso, não quer procurar mais, acho que mais é isso. [...] A própria pessoa desse grupo aí, não querem” (Rogério, 44 anos, Belo Horizonte).

A fala de Rogério permite que identifiquemos o uso do "Discurso do não querer", pois afirma que a própria pessoa não quer buscar o serviço de saúde. Assim, é possível identificar uma das características desse discurso, que é a culpabilização dos sujeitos. Segundo esse discurso, não se têm dados ou informações sobre as necessidades para o cuidado em saúde da população LGBT porque essa população não quer estar no serviço de saúde. É como se fosse do indivíduo a responsabilidade total por acessar e usufruir de uma USF. Rogério aponta sujeitos que desistem, como se fossem pessoas fracas, sem vontade o suficiente para seguirem na luta por si próprias.

Rogério também não nomeia a população à qual se refere. Diz “esse grupo aî". O grupo não está aqui, próximo. Está aí, abandonado, sem local, sem identidade, sem necessidade, sem querer, sem nome e sem cuidado. O silenciamento nesse caso se dá pela distância, pela indiferença, pela recusa em nomear. Aqui temos representada a noção de sujeito abjeto, conforme elucidado por Butler ${ }^{20}$, como sendo essencialmente seres abjetos, ou seja, aqueles que ainda não são "sujeitos”. Trata-se então de um repúdio, que cria a valência da "abjeção", e seu status para o sujeito, como um espectro ameaçador.

O "Discurso do não querer" é composto também por falas que dizem respeito a uma construção que, a princípio, parece enaltecer a autonomia do sujeito, fator essencial no empoderamento para o cuidado em saúde. Porém, esse discurso acaba por colocá-lo como único responsável pelo seu processo de saúde-adoecimento-cuidado, desconsiderando o papel dos outros atores sociais, bem como os marcadores sociais que (re)produzem as desigualdades.

A fala de Hilda demonstra como esse suposto respeito à autonomia tem sido frequentemente utilizado no cuidado à população LGBT na Estratégia Saúde da Família. "Isso parte sempre do próprio paciente. 'Olha eu sou, e eu quero acompanhar, ou quero buscar um apoio, eu quero uma mudança, eu quero o meu nome social' Então sempre parte deles mesmo”. (Hilda, 27 anos, Uberlândia)

O relato de Diógenes reforça essa característica de uma autonomia unilateral que o "Discurso do não querer" possui. "Eles nunca expuseram os desejos de fazer algum tratamento específico, uso de hormônio, essas coisas. Nunca me falaram, né? Talvez eu poderia estar abordando isso, não sei”. (Diógenes, 46 anos, Uberlândia)

Ou seja, deveria partir do(a) usuário(a), sempre, a responsabilidade por seu cuidado. Segundo Souza Soares \& Camargo Jr ${ }^{21}$, o primeiro princípio constitutivo de uma concepção complexa da autonomia passa a ser sua característica relativa e relacional, inseparável da dependência, ou seja, é preciso superar uma ideia ou um objetivo de se chegar a uma autonomia absoluta. Pensar isto no processo saúdeadoecimento-cuidado, segundo os autores, significa defender não a autodeterminação do paciente pura e simples, mas, ao contrário, o fortalecimento das relaçóes entre pacientes e profissionais da saúde, entre pacientes e seus familiares, porque essas redes de autonomia/dependência passam a ser vistas como fundamentais para o cuidado e para a saúde. 


\section{Considerações finais}

É possível compreender como o "Discurso da não diferença”, o "Discurso do não saber” e o "Discurso do não querer” são potencializadores do silenciamento de questốes envolvendo as condições de saúde da população LGBT, afastando-a do cuidado em saúde integral, equânime e universal. Assim, há que se considerar que as transformações das redes de saúde para o melhor atendimento da população LGBT também dependem das transformações no modo de pensar e de agir dos profissionais de saúde, uma vez que as questóes culturais informadas pela norma heterossexual influenciam de modo subjetivo o atendimento dos profissionais da saúde a essa população ${ }^{22}$.

A Política Nacional de Saúde Integral LGBT apresenta, em seu plano operativo, a "necessidade de identificar as necessidades de saúde de lésbicas, gays, bissexuais, travestis e transexuais e utilizá-las como critério de planejamento e definição de prioridades”. . Mas, apesar de propor a discussão das necessidades em saúde da população LGBT sob a perspectiva da determinação social do processo saúde-adoecimento-cuidado, ainda explicita, em seu texto, diversas necessidades de saúde alicerçadas no discurso médicocientífico. Nesse sentido, Cecílio9 apresenta uma proposição sobre a integralidade no cuidado, que permite compreender as necessidades e diferenças da população LGBT:

"No encontro do usuário com a equipe, haveriam de prevalecer, sempre o compromisso e a preocupação de se fazer a melhor escuta possível das necessidades de saúde trazidas por aquela pessoa que busca o serviço. [...] Assim, a integralidade da atenção, no espaço singular de cada serviço de saúde, poderia ser definida como o esforço da equipe de saúde de traduzir e atender, da melhor forma possível, tais necessidades, sempre complexas mas, principalmente, tendo que ser captadas em sua expressão individual.”’ (p. 116)

Ou seja, o desafio das pessoas de uma equipe de saúde vai para muito além da superação de preconceitos e discriminaçóes contra a população LGBT. Atravessa, antes de qualquer coisa, o seu reconhecimento como humano, sujeito de direitos, com demandas específicas e necessidade de serviços de saúde que só ele pode dizer, mas que só dirá, se for acolhido no serviço de saúde.

O recorte do objeto dessa pesquisa - os relatos das(os) médicas(os) - pode ser fator limitante para compreender essa questão em sua complexidade. Assim, a execução da pesquisa incluindo outras cidades e perspectivas (usuários(as), gestores(as) e outros(as) profissionais das USF) pode superar essa limitação, ampliando resultados, discussóes e futuras intervenções em relação a essa temática.

Foi possível perceber, com esse trabalho, que os currículos de Medicina no Brasil devem reconhecer essa temática, compreendendo sua relevância para a formação médica no país hoje. Há que se compreender também a complexidade do tema e buscar trabalhar seus aspectos históricos, políticos, culturais, bem como desenvolver estratégias efetivas de intervenção no acolhimento e na qualidade da atenção integral à saúde da população LGBT. 


\section{Contribuições dos autores}

Todos os autores participaram ativamente de todas as etapas de elaboração do manuscrito.

\section{Agradecimentos}

Ao Prof. Gustavo Antonio Raimondi, que, por meio de suas generosas reflexóes e debates, nos permitiu aprimorar este texto.

À Sra. Cristina Apparecida dos Santos Crovato, que além do incentivo, nos auxiliou na organização da agenda de entrevistas em Belo Horizonte-MG junto à Secretaria Municipal de Saúde dessa cidade.

Às pessoas da pesquisa "Análise do Acesso e da Qualidade da Atenção Integral à Saúde da população LGBT no Sistema Único de Saúde”, coordenada pelo Núcleo de Saúde Pública da Universidade de Brasília, pela idealização da pesquisa em âmbito nacional, bem como pela contribuição para que tudo pudesse ocorrer em Uberlândia e Belo Horizonte.

Ao Ministério da Saúde, pelo financiamento da pesquisa.

Às Secretarias Municipais de Saúde de Uberlândia e Belo Horizonte, por aceitarem a realização da pesquisa e facilitarem a realização de todo o processo de coleta de dados.

Às equipes de Saúde da Família, que se organizaram em seus dinâmicos processos de trabalho para, em meio ao cotidiano de suas práticas, nos receber com muita disposição para participar da pesquisa.

Às(aos) médicas(os) que aceitaram participar da pesquisa e, assim, dedicar parte de seu precioso tempo no cuidado com as pessoas, para refletir e discutir sobre o cuidado prestado à população LGBT na Estratégia Saúde da Família no SUS.

Às pessoas da população LGBT, razão primordial deste estudo, nosso eterno agradecimento e sincero respeito por todas as lutas e conquistas até então alcançadas. Ainda veremos, um dia, um mundo melhor, transformado, onde o respeito às diferenças seja pleno e a convivência entre as pessoas seja harmoniosa e construtiva.

\section{Direitos autorais}

Este artigo está licenciado sob a Licença Internacional Creative Commons 4.0, tipo BY (https://creativecommons.org/licenses/by/4.0/deed.pt_BR).

\section{Referências}

1. Melo APL. "Mulher Mulher" e "Outras Mulheres": gênero e homossexualidade(s) no Programa de Saúde da Família [dissertação]. Rio de Janeiro: Instituto de Medicina Social, Universidade do Estado do Rio de Janeiro; 2010.

2. Sousa MFD, Hamann EM. Programa Saúde da Família no Brasil: uma agenda incompleta? Cienc Saude Colet. 2009; 14 Suppl 1:1325-35.

3. Malta DC, Santos MAS, Stopa SR, Vieira JEB, Melo EA, Reis AACD. A cobertura da Estratégia de Saúde da Família (ESF) no Brasil, segundo a Pesquisa Nacional de Saúde, 2013. Cienc Saude Colet. 2016; 21(2):327-38. 
4. Brasil. Ministério da Saúde. Portaria no 2.836, de 1 de Dezembro de 2011. Institui, no âmbito do Sistema Único de Saúde (SUS), a Política Nacional de Saúde Integral de Lésbicas, Gays, Bissexuais, Travestis e Transexuais (Política Nacional de Saúde Integral LGBT). Brasília: Ministério da Saúde; 2011.

5. Moll J, Krieger P, Moreno-Walton L, Lee B, Slaven E, James T, et al. The prevalence of lesbian, gay, bisexual, and transgender health education and training in emergency medicine residency programs: what do we know? Acad Emerg Med. 2014; 21(5):60811.

6. Rufino AC, Madeiro AP, Girão MJ. O ensino da sexualidade nos cursos médicos: a percepção de estudantes do Piauí. Rev Bras Educ Med. 2013; 37(2):178-85.

7. Lionço T. Que direito à saúde para a população GLBT? Considerando direitos humanos, sexuais e reprodutivos em busca da integralidade e da equidade. Saude Soc. $2008 ; 17(2): 11-21$.

8. Moscheta MS. Responsividade como recurso relacional para a qualificação da assistência a saúde de lésbicas, gays, bissexuais, travestis e transexuais [tese]. Ribeirão Preto: Universidade de São Paulo; 2011.

9. Cecilio LCO. As necessidades de saúde como conceito estruturante na luta pela integralidade e equidade na atenção em saúde. In: Pinheiro R, Mattos RA, organizadores. Os sentidos da integralidade na atenção e no cuidado à saúde. Rio de Janeiro: UERJ, Abrasco; 2001.

10. Batistella C. Saúde, doença e cuidado: complexidade teórica e necessidade histórica. In: Fonseca AF, Corbo AMD, organizadores. O território e o processo saúde-doença. Rio de Janeiro: EPSJV, Fiocruz; 2007.

11. Burr V. An introduction to social construtionism. Londres: Routlege; 1995.

12. Brasil. Ministério da Saúde. Portaria no 2.436, de 21 de Setembro de 2017. Aprova a Política Nacional de Atenção Básica, estabelecendo a revisão de diretrizes para a organização da Atenção Básica, no âmbito do Sistema Único de Saúde (SUS). Brasília: Ministério da Saúde; 2017.

13. Daniel H, Butkus R. Lesbian, gay, bisexual, and transgender health disparities: executive summary of a policy position paper from the american college of physicians. Ann Int Med. 2015; 163(2):135-48.

14. Fredriksen-Goldsen KI, Simoni JM, Kim H-J, Lehavot K, Walters KL, Yang J, et al. The health equity promotion model: reconceptualization of lesbian, gay, bisexual, and transgender (LGBT) health disparities. Am J Orthopsychiatr. 2014; 84(6):653-63.

15. Mello L, Avelar RB, Maroja D. Por onde andam as políticas públicas para a população LGBT no Brasil. Soc Estado. 2012; 27(2):289-312.

16. Brasil. Ministério da Educação. Resolução no 3, de 20 de Junho de 2014. Institui Diretrizes Curriculares Nacionais do Curso de Graduação em Medicina e dá outras providências. Brasília: Ministério da Educação; 2014.

17. Glass RD. Revisitando os fundamentos da educação para a libertação: o legado de Paulo Freire. Educ Real. 2013; 38(3):831-51.

18. Baker K, Beagan B. Making assumptions, making space: an anthropological critique of cultural competency and its relevance to queer patients. Med Anthropol Q. 2014; 28(4):578-98.

19. McNair RP, Hegarty K. Guidelines for the primary care of lesbian, gay, and bisexual people: a systematic review. Ann Fam Med. 2010; 8(6):533-41. 
20. Butler J. Corpos que pesam: sobre os limites discursivos do "sexo". In: Louro GL, organizador. O corpo educado - pedagogias da sexualidade. 3a ed. Belo Horizonte: Autêntica; 2013. p. 110-25.

21. Souza Soares JCR, Camargo Jr KR. A autonomia do paciente no processo terapêutico como valor para a saúde. Interface (Botucatu). 2007; 11(21):65-78.

22. Rodrigues M, Ferro LF. Saúde e população LGBT: demandas e especificidades em questão. Psicol Cienc Prof. 2012; 32(3):552-63.

The aim of this study was to identify discourses on access to and quality of comprehensive care for lesbian, gay, bisexual, and transgender (LGBT) people adopted by doctors working in the Family Health Strategy. This article reflects upon how these discourses influence the provision of healthcare to LGBT population. Fifteen doctors from Uberlândia and Belo Horizonte, in the State of Minas Gerais, Brazil, participated in the study. The analysis of the interviews was underpinned by the principles of social constructionism and based on the following analytical categories: the "no difference discourse", "don't know discourse", "don't want discourse". Insights were gained into how these discourses prompt the silencing of issues related to the health status of LGBT people, alienating them from comprehensive universal healthcare. We conclude that to improve care provision for this population, healthcare providers need to change their approach. In this respect, training is urgently needed to improve the accessibility and delivery of comprehensive health services to LGBT people.

Keywords: Sexual and gender minorities. Public health. Access to health services. Comprehensive healthcare.

El objetivo es identificar los discursos sobre el acceso y la calidad de la atención integral de la salud de la población de Lesbianas, Gais, Bisexuales, Travestis y Transexuales (LGBT) entre médicas(os) de la Estrategia Salud de la Familia, reflexionando sobre cómo esos discursos pueden causar impacto sobre el cuidado de salud de la población LGBT. Participaron 15 médicas(os) en Uberlândia y Belo Horizonte, Minas Gerais, Brasil. El análisis de las entrevistas siguió los supuestos teóricos del Construccionismo Social. Se construyeron tres categorías de análisis: "Discurso de la no-diferencia", "Discurso del no-saber" y "Discurso del no-querer". Fue posible comprender cómo esos discursos son potenciadores del silenciamiento de cuestiones que envuelven las condiciones de salud de la población LGBT, apartándola del cuidado de salud integral, ecuánime y universal. Concluimos que la mejor atención de esa población depende de cambios en la actuación de los profesionales de salud, siendo urgente su formación y calificación para una salud LGBT integral.

Palabras clave: Minorías sexuales y de género. Salud pública. Acceso a los servicios de salud. Asistencia integral de la salud. 